Article

\title{
A Modification of Offset Strip Fin Heatsink with High-Performance Cooling for IGBT Modules
}

\author{
Ali Yahyaee* *D, Amir Sajjad Bahman $(D)$ and Frede Blaabjerg $(\mathbb{D}$ \\ Department of Energy Technology, Aalborg University, 9220 Aalborg, Denmark; asb@et.aau.dk (A.S.B.); \\ fbl@et.aau.dk (F.B.) \\ * Correspondence: ayn@et.aau.dk; Tel.: +45-81-941-883
}

Received: 17 December 2019; Accepted: 29 January 2020; Published: 7 February 2020

\begin{abstract}
For reliability and thermal management of power devices, the most frequently used technique is to employ heatsinks. In this work, a new configuration of offset strip fin heatsink based on using the concept of curvy fins and U-turn is proposed with the aim of improving the heat transfer performance. With this aim, a three-dimensional model of heatsink with Silicon Insulated-Gate Bipolar Transistors (IGBTs) and diodes, solder, Direct Bonded Copper (DBC) substrate, baseplate and thermal grease is developed. Richardson's extrapolation is used for increasing the accuracy of the numerical simulations and to validate the simulations. To study the effectiveness of the new offset design, results are compared with conventional offset strip fin heatsink. Results show that in aspects of design of heatsinks (including heat transfer coefficient, maximum chip temperature and thermal resistance), the new introduced model has advantages compared to the conventional offset strip fin design. These enhancements are caused by the combination of the longer coolant passage in the heatsink associated with generation of disturbance and recirculation areas along the curvy fins, creation of centrifugal forces in the U-turn, and periodic breaking up boundary layers. Also, it is shown that due to narrower passage and back-and-forth route, the new introduced design can handle the hot spots better than conventional design.
\end{abstract}

Keywords: curvy fins; heatsink; numerical simulation; offset strip fin; thermal management; U-turn

\section{Introduction}

With the rising awareness of necessity of sustainable energy systems, power electronics (PE) technologies are increasingly becoming the key technology of various energy conversion systems. The insulated-gate bipolar transistor (IGBT) has been used as one of the key components in PE. Advances in PEs has led to the need for manufacturing of highly compact IGBTs, associated with high heat density generation. This trend stresses the necessity of studies regarding design of cooling systems and providing proper thermal management of the IGBT modules to avoid intense heating and even burn-out. An IGBT module can be seen in Figure 1.

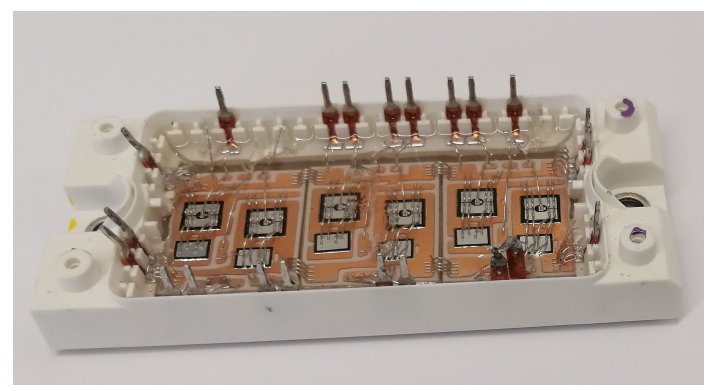

Figure 1. An unpacked IGBT module. 
As a solution to the problem of high heat density, heatsinks have been introduced as additional coolers for PE and they are widely used. A heatsink, which consists of several microchannels, is a promising approach to cool electronic chips with a high rate of heat generation. A heatsink with conventional straight microchannels can be seen in Figure 2a.

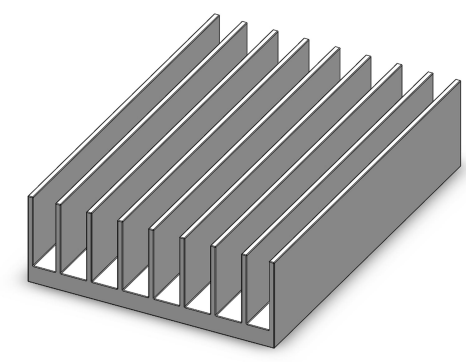

(a)

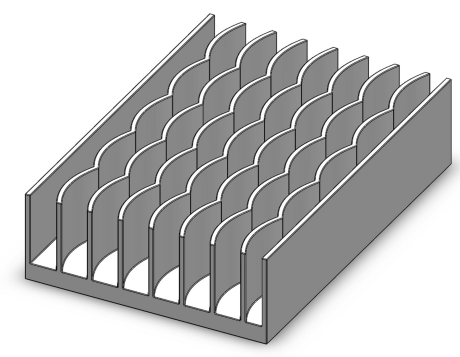

(c)

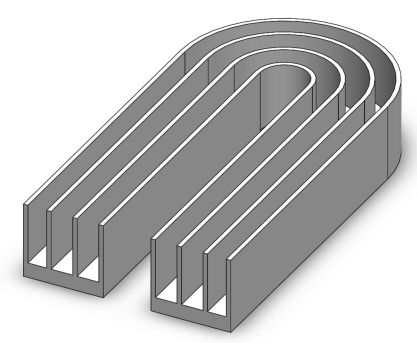

(b)

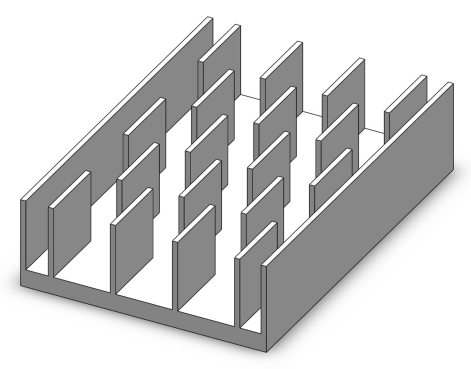

(d)

Figure 2. Schematics of a heatsink with (a) Conventional straight microchannels, (b) U-turn path, (c) Parallel curvy microchannels, (d) Offset strip fins.

The design and structure of microchannels have a significant impact on hydraulic and thermal performance of heatsinks. In the last 50 years, much effort has been devoted to enhance the heat dissipation ability of heatsinks in respect to the heatsink materials and fabrication methods [1-3], different arrangements of equipment in cooling loops and systems [4], optimization tools [5], different coolants [6], different phases of coolants [7,8], combination of thermoelectric coolers and heatsinks [9], compact sandwiched press-pack $\mathrm{SiC}$ power module [10], using nanofluids [11], heat exchangers designs [12], using porous materials in heatsinks [13] and different channel shapes and designs [14].

Different flow profiles are created by passing fluids through different heat sink configurations, causing different temperature profiles and different cooling abilities. A structure which is commonly used in heat exchangers and can improve the heat transfer rate is the U-turn (Figure 2b). Such a path creates centrifuge forces and prolongs the cooling path inside the heatsink, both of which contribute to the rising cooling efficiency.

Mohammed et al. [14] investigated different rectangular and parallel channel shapes including curvy microchannels (Figure 2c). Their simulation results show that the curvy microchannels will improve the heat transfer coefficient compared to the conventional straight microchannels.

One of the high-performance configurations is offset strip fin (Figure 2d). For a given pressure drop and heat source base area, the offset strip fin heatsink offers a better thermal hydraulic performance than the conventional straight microchannels [15].

In recent years, many studies have been conducted on offset strip fin configurations, investigating different structures ( $Z$ type and $H$ type) [16,17], the thermal and hydraulic behavior of single phase flow experimentally [18] and two phase flow [19,20], predicting the thermo-hydraulic characteristics 
numerically [21], pressure drop and heat transfer correlations for single phase flow [22,23] and two phase flow [19].

The development of new generation of power devices, such as wide bandgap devices (WBG) and high-performance converter topologies leads to requiring of novel heatsink designs to overcome higher heat flux and making new designed components. In this paper, to follow the efforts for improving heat transfer rate of cooling systems and considering the advantages of offset design, curvy fins and U-turn path, a new and modified configuration based on mentioned heatsinks concept (offset strip fin, curvy fins and U-type design) is introduced and investigated. This new design is proposed to extend the current limitations of the heat transfer dissipation of conventional offset strip fin design.

\section{Numerical Details and Layouts for Analysis}

\subsection{Computational Domain}

To simulate the convective flow and heat conduction in new introduced cooling configurations, a 3D solid-fluid conjugate heat transfer model is made. The simulations are conducted using finite element method based on the commercial package-Comsol Multiphysics 5.4. This software provides a convenient and robust graphical user interface. This easy-to-work interface facilitates to set up a simulation model, to run it and to visualize the results.

To model the heat sink, the conjugate heat transfer module is used. Continuity, Navier-Stokes and energy equations for both the fluid and solid subdomains are solved, simultaneously. In addition, conjugate heat transfer module provides necessary tools to do analysis of heat sink model in conduction and convection heat transfer.

An Insulated-Gate Bipolar Transistor (IGBT) module is placed on a heatsink. IGBT chip and diode chip on the top and other metal and isolation layers at the bottom are illustrated in Figure 3a,b. It should be noted that in this model (Figure 3b) larger chips (IGBTs) and smaller chips (diodes) produce $50 \mathrm{~W}$ and $30 \mathrm{~W}$, respectively. Thermal characteristics of the materials used in the IGBT module under study are given in Table 1. Also, the size of these layers can be seen in Table 2.

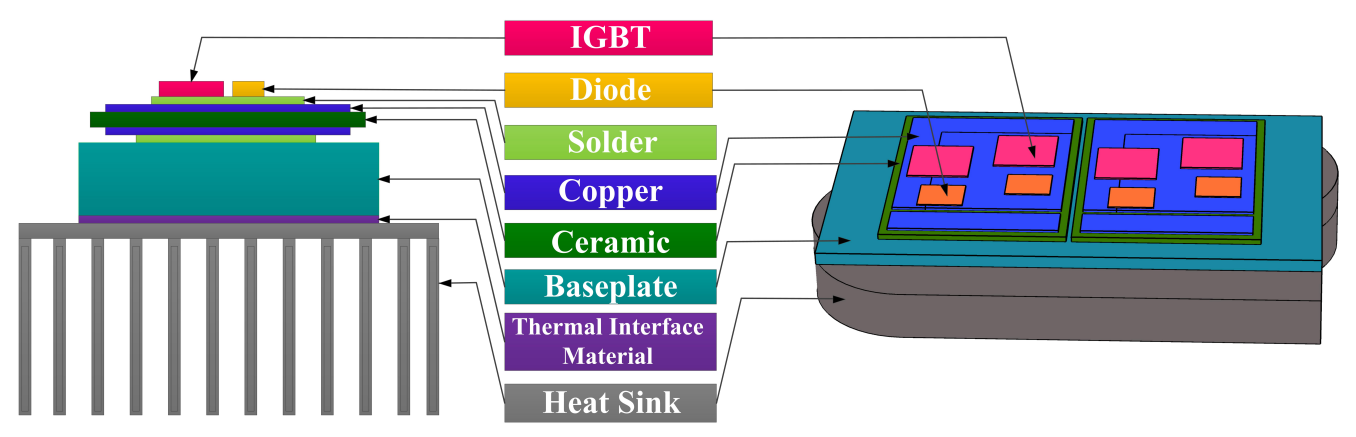

(a)

(b)

Figure 3. (a) An IGBT module with a heatsink and its different layers, (b) Schematic of the IGBT module modeled in Comsol Multiphysics.

Table 1. Material thermal properties of the IGBT module.

\begin{tabular}{cccc}
\hline Material & Density/ $\mathbf{k g m}$ & Specific $\mathbf{H e a t} / \mathbf{J k g}^{-\mathbf{1}} \mathbf{K}^{-\mathbf{1}}$ & Conductivity/ $\mathbf{W m}^{-\mathbf{1}} \mathbf{K}^{\mathbf{- 1}}$ \\
\hline Heatsink (Silicon) & 2330 & 705 & 140 \\
Baseplate (Copper) & 8954 & 384 & 395 \\
Ceramic $\left(\mathrm{Al}_{2} \mathrm{O}_{3}\right)$ & 3890 & 880 & 35 \\
Solder & 2600 & 1200 & 3 \\
Thermal grease & 7370 & 220 & 57 \\
\hline
\end{tabular}


Table 2. Geometric values of layers of IGBT module.

\begin{tabular}{cc}
\hline Description & Length $\times$ Width $\times$ Height \\
\hline Diode & $5.5 \times 4.78 \times 0.13 \mathrm{~mm}^{3}$ \\
Solder (under Diodes) & $5.5 \times 4.78 \times 0.025 \mathrm{~mm}^{3}$ \\
IGBT & $7.53 \times 7.6 \times 0.13 \mathrm{~mm}^{3}$ \\
Solder (under IGBTs) & $7.53 \times 7.6 \times 0.025 \mathrm{~mm}^{3}$ \\
Copper & $20.5 \times 28 \times 0.3 \mathrm{~mm}^{3}$ \\
Ceramic & $22.5 \times 30 \times 0.63 \mathrm{~mm}^{3}$ \\
Solder (between copper and baseplate) & $7.6 \times 0.025 \times 0.025 \mathrm{~mm}^{3}$ \\
Baseplate & $60 \times 36 \times 1.5 \mathrm{~mm}^{3}$ \\
Thermal grease & $60 \times 36 \times 0.01 \mathrm{~mm}^{3}$ \\
\hline
\end{tabular}

To study the effectiveness of this new design, results are compared with conventional version of the offset strip fin heatsink. Figure 4 shows the conventional offset strip fin along with the different parameters used to describe the geometry. Table 3 lists the different dimensions in Figure $4 a, b$. Schematics of the new offset design can be seen in Figure 4c.

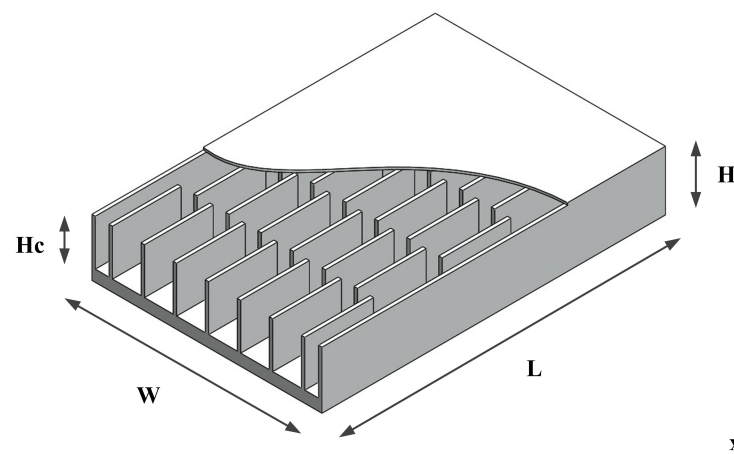

(a)

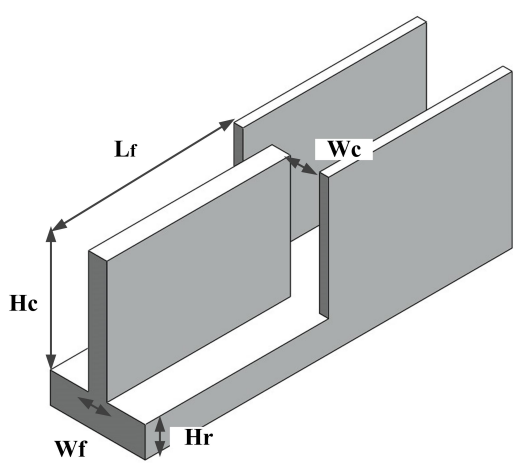

(b)

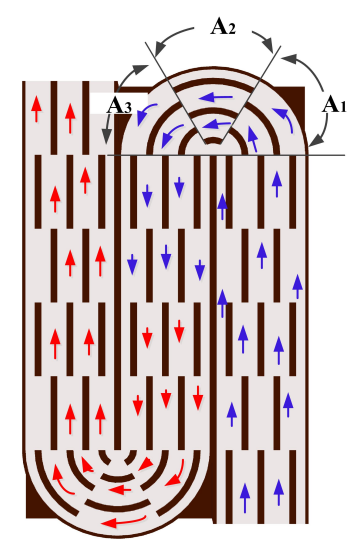

(c)

Figure 4. Geometries of (a) 3D Offset strip fin heatsink, (b) Detailed dimensions of a channel with fins, (c) New offset design (Blue and red arrows show inlet and outlet flow, respectively).

It should be noted that the coolant is water with an inlet temperature of $20^{\circ} \mathrm{C}$ and inlet mass flow rate in the range of $3-18.5 \mathrm{~cm}^{3} \mathrm{~s}^{-1}$. The flow regime is laminar in this mass flow range. The geometric parameters of $A_{1}, A_{2}$ and $A_{3}$ have been chosen based on some preliminary simulations to obtain the highest performance from a heat transfer point of view. 
Table 3. Dimensions of the heatsink.

\begin{tabular}{ccc}
\hline Sign & Description & Value \\
\hline$H$ & Heatsink height & $10 \mathrm{~mm}$ \\
$H_{c}$ & Channel height & $6 \mathrm{~mm}$ \\
$H_{r}$ & Rib height & $4 \mathrm{~mm}$ \\
$W$ & Heatsink width & $36 \mathrm{~mm}$ \\
$L$ & Heatsink length & $60 \mathrm{~mm}$ \\
$W_{f}$ & Fin width & $0.86 \mathrm{~mm}$ \\
$W_{c}$ & Channel width & $1.14 \mathrm{~mm}$ \\
$L_{f}$ & Fin length & $10 \mathrm{~mm}$ \\
$A_{1}$ & Curve angle & $40^{\circ}$ \\
$A_{2}$ & Curve angle & $100^{\circ}$ \\
$A_{3}$ & Curve angle & $40^{\circ}$ \\
\hline
\end{tabular}

\subsection{Grid Topology to Simulate}

Due to existence of sharp edges and offset fins, triangular, boundary layers and tetrahedral meshes are employed to obtain a suitable mesh model to achieve flow field and heat transfer characteristics of the proposed heatsink. A zoomed-in view of the mesh in the fluid is shown in Figure 5. As it can be seen in Figure 5a, close to the solid fin and in the fluid, the boundary layer mesh is used. This mesh is used when an intense gradient exists in the model. In this model, in the studied flow, there is a relatively intense velocity gradient that quickly ended at $U=0$ at the boundary.

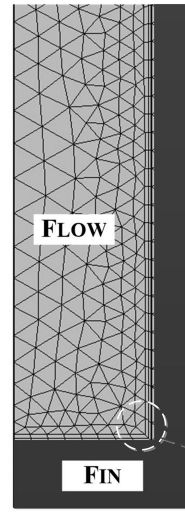

(a)

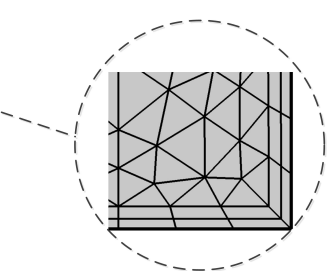

-...-

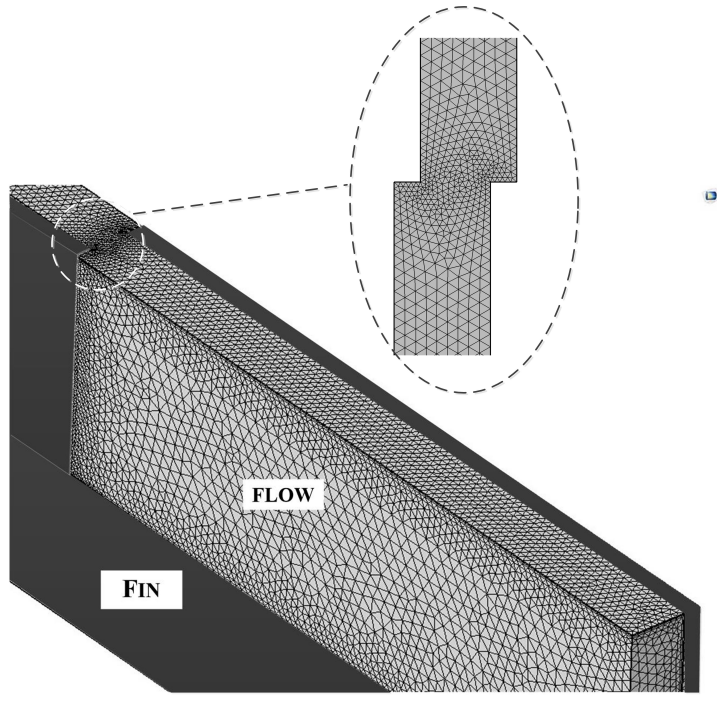

(b)

Figure 5. Mesh configuration to simulate the flow in the heatsink (a) Adjacent to boundary layers, (b) In sharp edges.

By moving away from the fluid and solid interface, anisotropic prismatic elements in the shape of hexahedral are used for simulating the fluid and the solid. As a result, a mesh which is finer in the water domain than the solid domain is created. Also, all sharp angles are identified and meshed by finer elements (Figure 5b).

Table 4 lists the different geometric parameters (which are used in Comsol multiphysics) of the mesh configuration. This table shows that the finest and least fine mesh belongs to wetted walls and IGBT module, respectively. 
Table 4. Geometric values of mesh configurations.

\begin{tabular}{cccc}
\hline & Max Element Size & Min Element Size & Max Element Growth Rate \\
\hline Fluid domain & $5.12 \mathrm{~mm}$ & $0.64 \mathrm{~mm}$ & 1.45 \\
IGBT module domain & $1.5 \mathrm{~mm}$ & $0.448 \mathrm{~mm}$ & 1.15 \\
Wetted walls & $0.829 \mathrm{~mm}$ & $0.0897 \mathrm{~mm}$ & 1.1 \\
\hline
\end{tabular}

\subsection{Richardson's Extrapolation}

Richardson extrapolation is a method to attain a higher-order estimation of the continuum value from a series of lower-order discrete values [24] and is used as a computational tool for increasing the accuracy of numerical simulations. Moreover, this method can be used to validate the simulation results $[25,26]$. Four different mesh structures with $0.5,1,2$ and 4 million cells are generated by increasing the number of grids. This grid structure sequence is generated with a constant refinement ratio $(r)$ of 2. The extrapolated exact numerical solution is estimated using Richardson's method. Roache [27] suggested the Grid Convergence Index (GCI) to estimate the required grid resolution. The GCI is defined as:

$$
\mathrm{GCI}=\frac{F_{\mathrm{S}}|\epsilon|}{r^{p}-1}
$$

where $F_{\mathrm{s}}$ is a safety factor, $\epsilon$ is the relative error between the two grids, $r$ is the grid refinement ratio and $p$ is the order of convergence. Roache [27] suggested safety factor $\left(F_{\mathrm{S}}\right)$ of 1.25 for such mesh study, confirming convergence of the mesh.

Using the GCI, the error band is calculated as follows:

$$
\text { Error band }=f_{\text {exact }} \pm f_{\text {exact }} \cdot G C I_{12}
$$

in which $f_{\text {exact }}$ is the approximate exact solution and 1 and 2 are grid structures.

The sensitivity of changes with number of cells on the thermal resistance $\left(R_{t}\right)$ is shown in Figure 6 along with the estimated exact solution and the error band estimated.

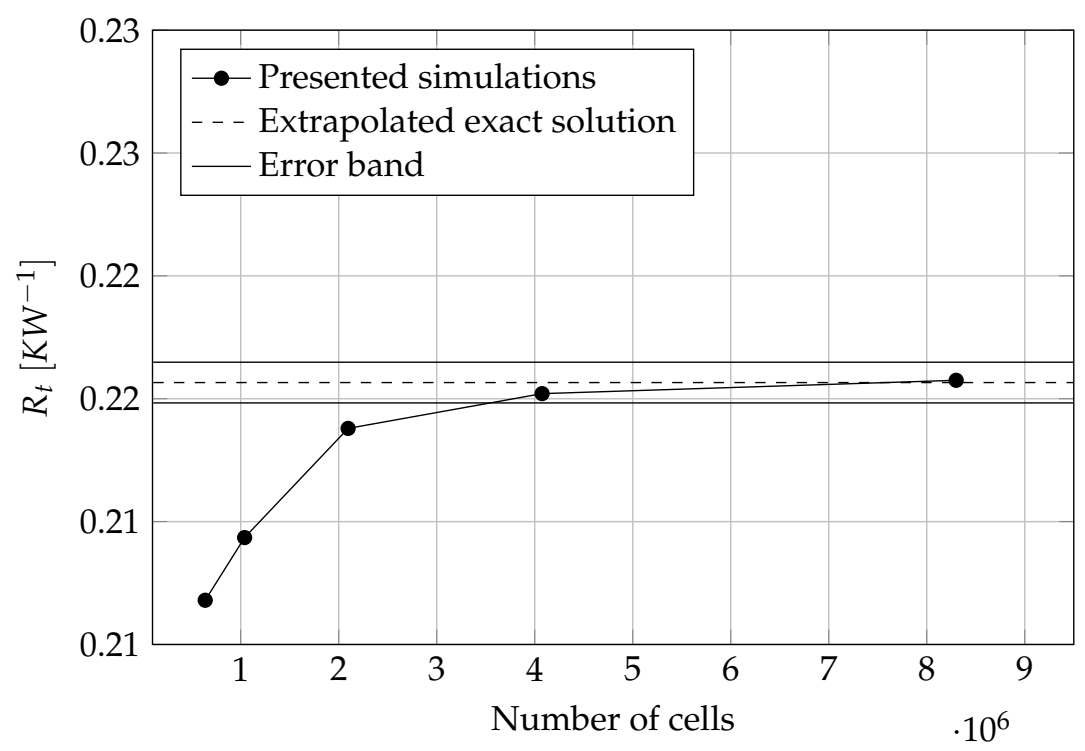

Figure 6. Sensitivity of changes with number of cells on thermal resistance $\left(R_{t}\right)$.

As shown in Figure 6, the thermal resistance $R_{t}$ is calculated by the mesh having 4 million cells within the error band and therefore this grid resolution is used for the rest of the simulations to obtain a valid solution. 


\section{Results and Discussion}

Results are shown in terms of thermal resistance, maximum chip temperature, heat transfer coefficient and pumping power. Also, the temperature and velocity distributions are presented for a visual comparison and investigating the reasons behind the differences in performance of two studied heatsink configurations.

\subsection{Velocity Distribution}

In this section, first the velocity distribution in this new offset configuration and its influence on heat transfer are shown in Figure 7. The information presented in this section will be used to explain why a high thermal and low pressure performance are achieved with this new design in next sections.

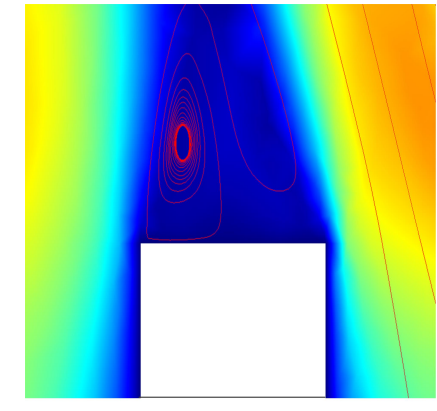

(a)

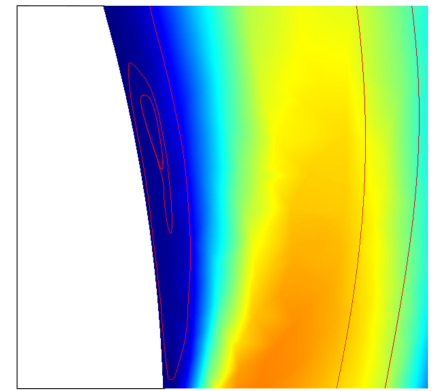

(b)

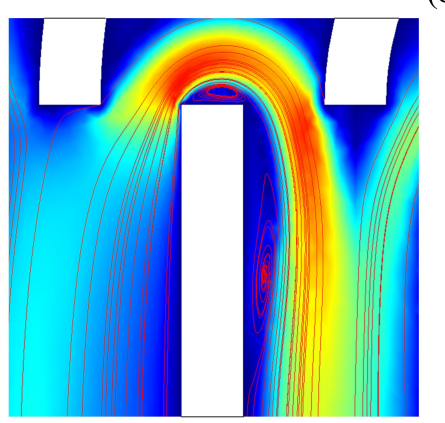

(c)

Figure 7. Recirculation areas at volumetric flow rate of $18 \mathrm{~cm}^{3} \mathrm{~s}^{-1}$ (a) After an offset fin, (b) In a curve and (c) In a U-turn (red lines show stream lines).

In offset strip fin configurations, the flow is facing obstacles and its direction is changing periodically. Therefore, large vortices and recirculation areas are created around the corners at the end of strip fins, as it can be seen in Figure 7a. These recirculation areas are associated with a better and easier mix of the hotter water adjacent to fins and the colder water flowing in the middle of the channels, and thereby improving the heat dissipation. Also, the thermal boundary layer development is disrupted periodically as a result of channel walls being broken up because of strip fin design.

In Figure 7b, creation of recirculation areas along the curvy fin is shown. For curvy configuration, dean vortices develop along the flow direction and can create recirculation areas and disturb the boundary layer.

In Figure 7c, the creation of recirculation areas in a $U$ path is shown. The Creation of a U-turn is associated with providing the chances of heat transfer between the inlet and outlet flow, and on the other hand, increasing the length of fluid flow passage inside the heatsink.

Moreover, U-turns cause centrifugal forces that can contribute to the creation of secondary flows and recirculation areas. These leads to strengthen the mixing of flow adjacent to walls and in the middle 
of channels, which cause making convective heat transfer stronger. As it can be seen, streamlines in the U-turn are denser than those in straight paths, showing that the velocity is higher in this area.

\subsection{Temperature Uniformity}

In a reliable design of power module heatsink, it is important to cool down all chips uniformly. This will improve the current sharing and loss distribution among the chips and enhance the whole lifetime of the power module. Distribution of temperature in chips is investigated and presented in Figure 8. It can be seen that the temperature distribution is better in the new offset design and temperature in the chip areas (hot spots) is lower compared to the conventional offset heatsink. The back-and-forth path (serpentine passage) in this new design is the main reason of this ability to face hot spots.

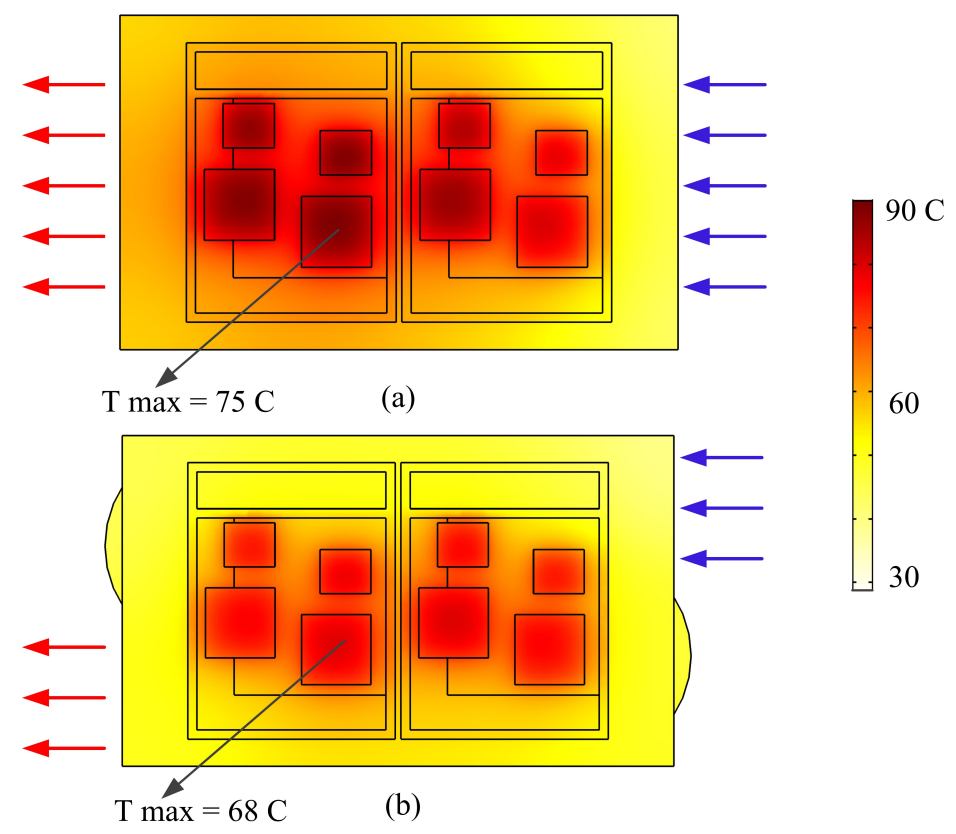

Figure 8. Temperature distribution from chips point of view at volumetric flow rate of $18 \mathrm{~cm}^{3} \mathrm{~s}^{-1}$ in (a) Offset strip fin design, (b) New offset design.

\subsection{Thermal Resistance}

Thermal resistance is the ratio of the temperature difference between the two faces of a heatsink to the heat flux. In heatsinks, the higher the thermal resistance, the lower is the heat dissipation and it has less ability to cool down power devices. Thermal resistance is defined as:

$$
R_{t}=\frac{\left(T_{\max }-T_{\min }\right)}{q A_{h}}
$$

in which, $T_{\max }$ is maximum temperature, $T_{\min }$ is minimum temperature, $q$ is the heat flux and $A_{h}$ is the area of heater surface.

Figure 8 shows that for both configurations the maximum temperature in the system is occurring in the third IGBT from the inlet, due to geometric position of this IGBT and also thermal coupling between the chips. As shown in Figure 9, minimum temperature of heatsink occurs at inlet area. At inlet area, the temperature of coolant is at its lowest value and this area is far from the hot spots. Therefore, minimum temperature of heatsink will be at inlet areas. In this study, the thermal resistance is calculated between the IGBT and the inlet area (maximum and minimum temperature). 

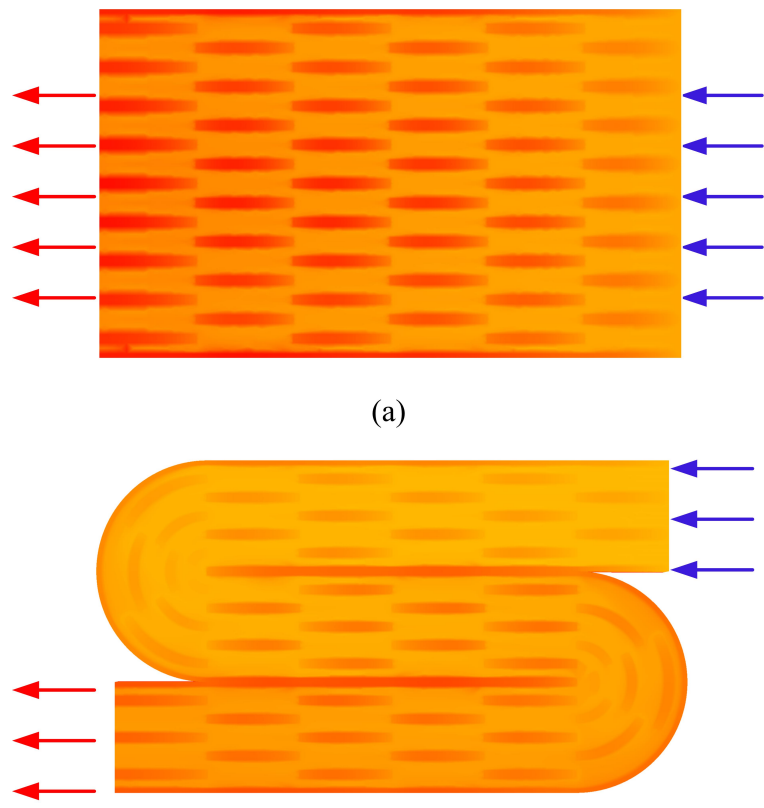

(a)

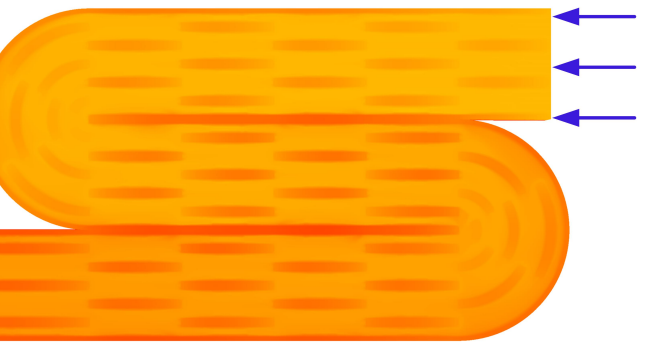

(b)

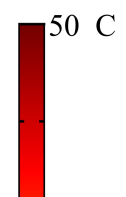

$-40$

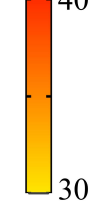

Figure 9. Temperature distribution from heatsink point of view at volumetric flow rate of $18 \mathrm{~cm}^{3} \mathrm{~s}^{-1}$ in (a) Offset strip fin design, (b) New offset design.

Another point, which is worthy of mention in Figure 9b, is temperature profile in the area of U-turns. As the flow progresses in the channel, the temperature should increase. However, as it can be seen, the temperature is lower in the U-turn areas than fins before the U-turn areas. This decrease in the temperature is caused by the combinative effects generation of disturbance and recirculation areas along the curvy fins and creation of centrifugal forces in the U-turn (Section 3.1, Figure 7b,c).

Figure 10 shows that the thermal resistance for both designs is decreasing by the increase of volumetric flow. It can be seen that the thermal resistance of the new offset design is lower than the conventional one $(10-15 \%)$.

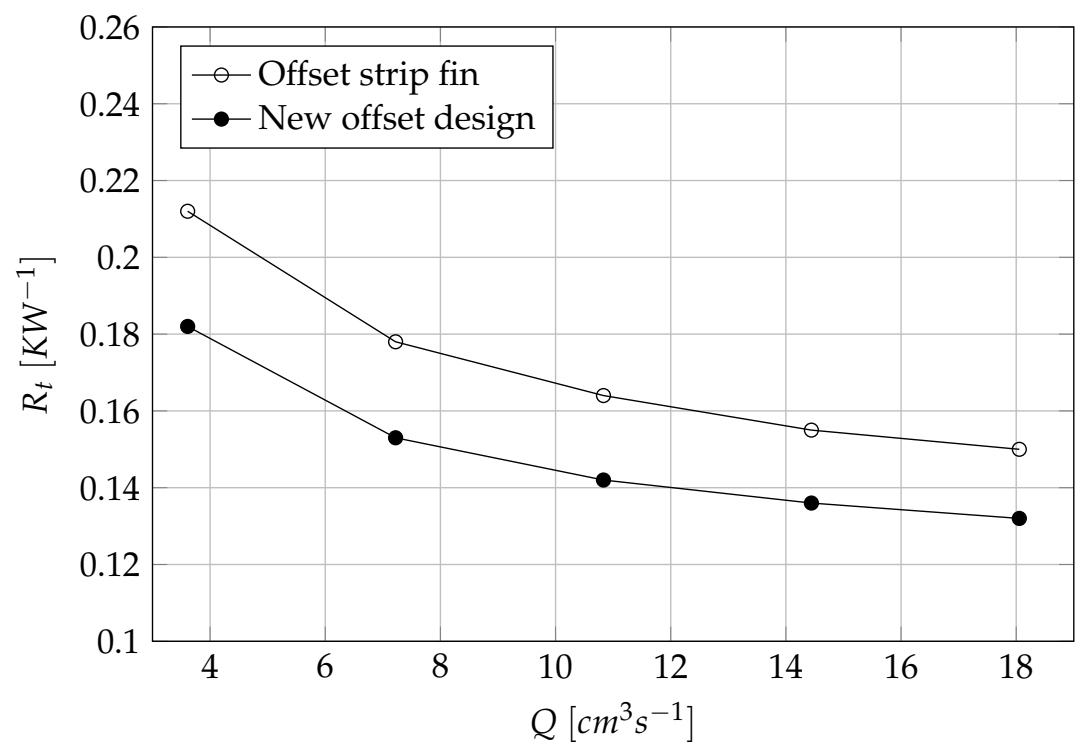

Figure 10. Thermal resistance $\left(R_{t}\right)$ in different volumetric flow rates $(Q)$ for conventional offset strip fin design and new offset design. 


\subsection{Maximum Chip Temperature}

In Figure 11, comparison of the maximum chip temperature for the new introduced design and conventional offset strip fin design is presented as a function of different volumetric flow rates. These values for different designs of heatsinks either new or conventional one decreases with the increase of volumetric flow rate. Also, this figure shows that the maximum chip temperature values of new introduced heatsink is lower than those of traditional offset strip fin heatsink for all the modeled volumetric flow rate. This decrease is in the range of $8-11 \%$ for different volumetric flow rates.

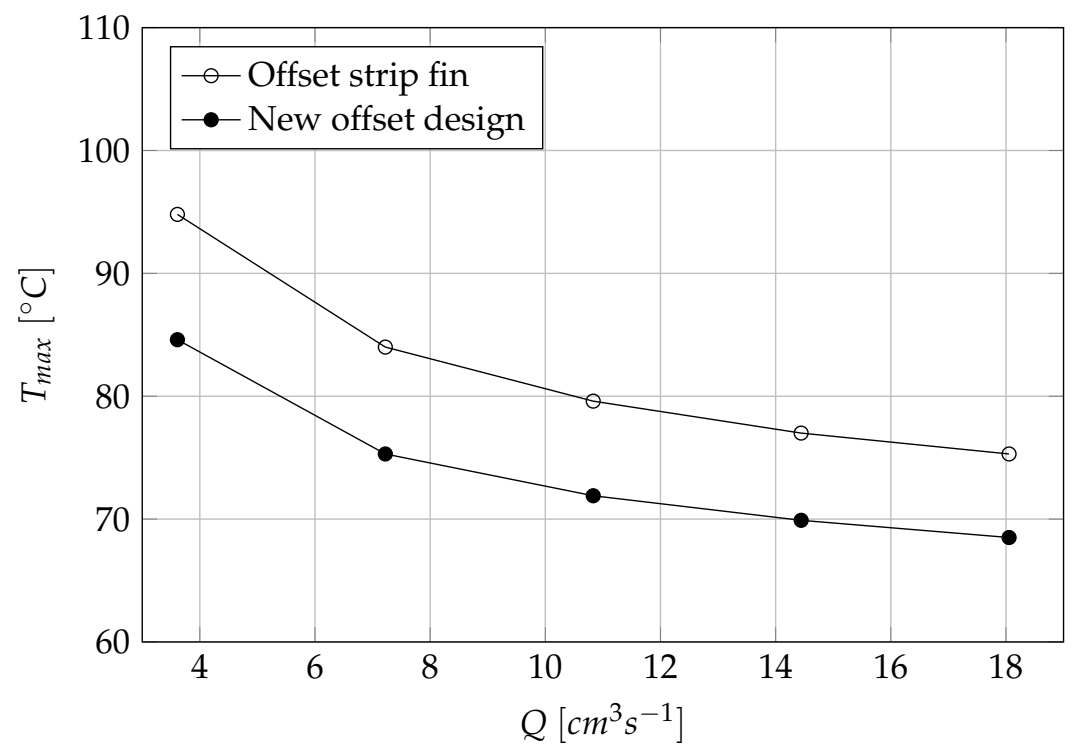

Figure 11. Maximum chip temperature $\left(T_{\max }\right)$ in different volumetric flow rates for conventional offset strip fin design and new offset design.

\subsection{Heat Transfer Coefficient}

Heat transfer coefficient is considered to be a quantitative characteristic of convective heat transfer between a fluid medium (water) and the surface (wall) flowed over by the fluid [28]. It is defined as:

$$
h=\frac{q A_{h}}{A_{c}\left(T_{i, a v}-T_{f, a v}\right)}
$$

in which, $q$ is the heat flux, $A_{h}$ is the area of heater surface, $A_{c}$ is contact area of fluid and solid, $T_{i, a v}$ is average temperature of the interface of fluid and solid, $T_{f, a v}$ is average temperature of fluid and $D_{h}$ is hydraulic diameter which is defined as:

$$
D_{h}=\frac{4 A_{s}}{P}
$$

where $A_{S}$ and $P$ are cross-section area of channel and wetted perimeter of channel, respectively.

Results show that the new offset serpentine design brings 65-72\% growth in heat transfer coefficient (Figure 12).

These enhancements are caused by the combinative effects of a longer coolant passage in the heatsink associated with back-and-forth route, generation of disturbance and recirculation areas along the curvy fins, creation of centrifugal forces in the U-turn (Section 3.1), and periodic breaking up boundary layers. 


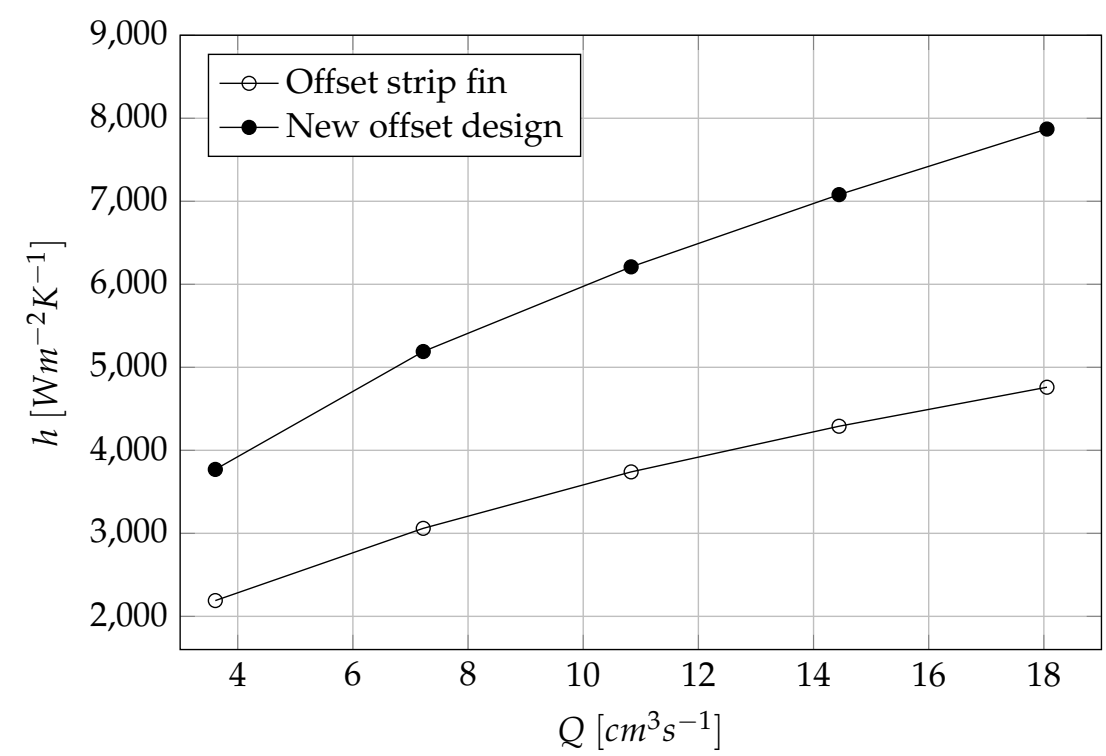

Figure 12. Heat transfer coefficient $(h)$ in different volumetric flow rates for conventional offset strip fin design and new offset design.

The advantage of having U-turns becomes apparent when studying the local heat transfer coefficient of the new offset design shown in Figure 13. Heat transfer coefficient enhancement is much larger in the region of U-turns; and the highest heat transfer coefficient is happening in the second U-turn. Also it can be seen, the line of the local heat transfer coefficients have non-linear distribution. It should be noted that the local heat transfer coefficient is calculated using constant heat flux under the heat sink.

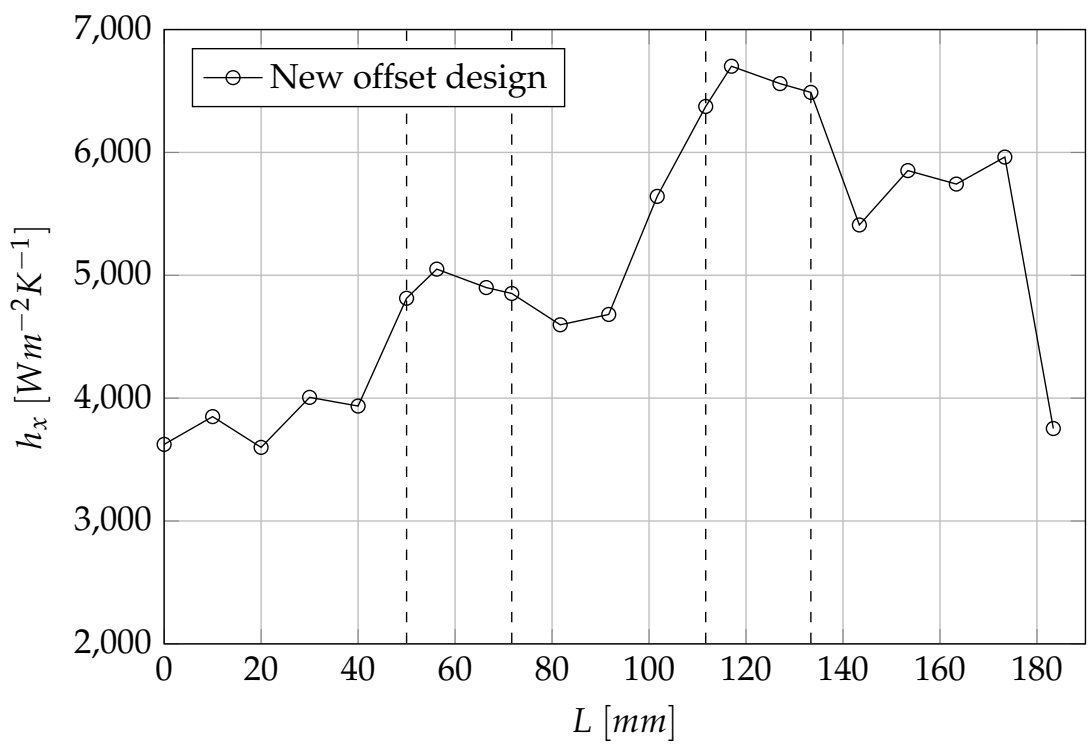

Figure 13. Local heat transfer coefficient $\left(h_{x}\right)$ enhancement of new offset design as a function of position within a serpentine passage at volumetric flow rate of $3.6 \mathrm{~cm}^{3} \mathrm{~s}^{-1}$ (start and end of each U-turn is shown by dashed lines).

\subsection{Pumping Power}

The pumping power which is needed to circulate the coolant in the heatsink versus volumetric flow rate is studied in Figure 14. Pumping power is defined as:

$$
P_{p}=Q \Delta p
$$


where $Q$ is volumetric flow rate and $\Delta p$ is pressure drop.

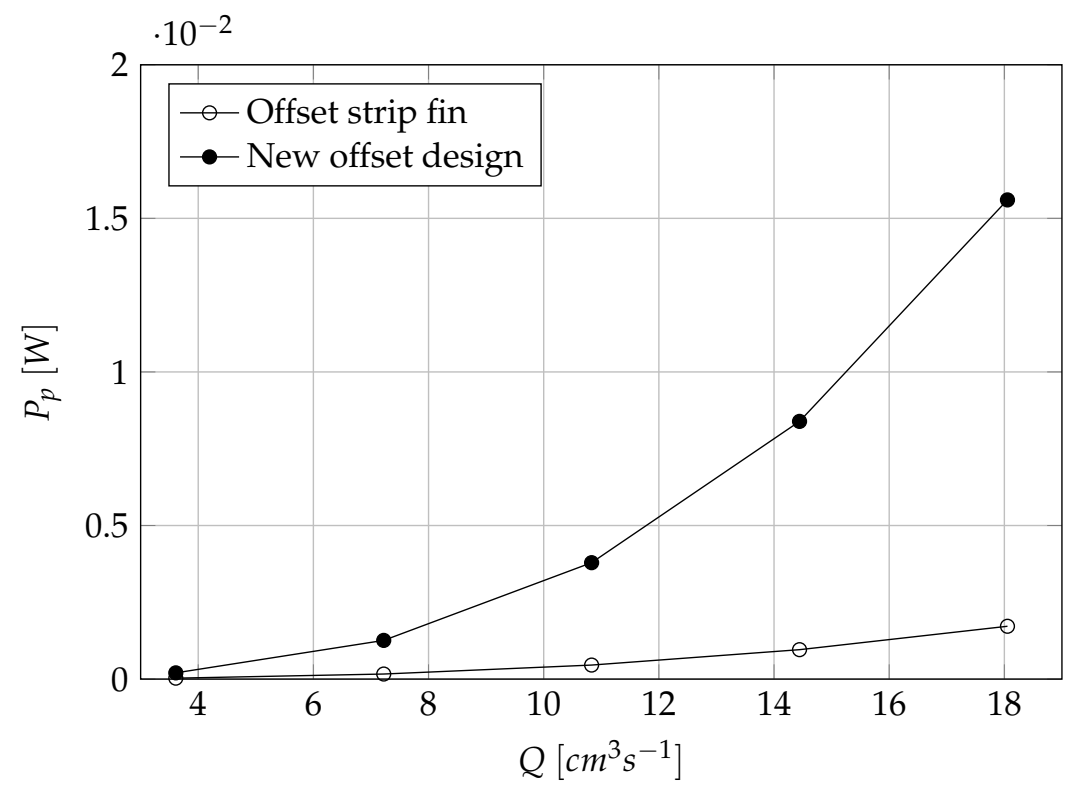

Figure 14. Pumping Power $\left(P_{p}\right)$ in different volumetric flow rates for conventional offset strip fin design and new offset design.

As it can be seen in Figure 14, a downside of the new design is the large increase in the pumping power required to circulate the water through the microchannels.

It should be noted that these values of pumping power are just in the order of $0.01 \mathrm{~W}$. Considering Equation (6) and the fact that volumetric flow rate is equal for both configurations, it can be concluded that pressure drop is higher in the new design than the conventional one. Pressure drop in the channel is defined by:

$$
\Delta p \sim \frac{\rho L V^{2}}{2 D_{h}}
$$

where $\rho$ is the fluid density, $V$ is flow velocity, $L$ is length of flow passage and $D_{h}$ is the hydraulic diameter. With respect to Equation (7), a part of this higher pressure drop is caused by the longer path and also higher velocity of flow in the new offset design (as a result of smaller cross-section area in new design compared to conventional one).

As depicted in Figure 15, the flow velocity in the conventional offset strip fin configuration is mostly in the range of $0.1-0.3 \mathrm{~m} / \mathrm{s}$, while it is mostly in the range of $0.4-0.6 \mathrm{~m} / \mathrm{s}$ for the new offset design.

Moreover, Figure 15b shows that the velocity distribution in the first and second U-turn is different. This phenomenon is the result of the difference in fin configurations in the first and second U-turns.

In other words, the number of fins in the first and second U-turns is different.

Also, it is worthy of mention that there are three fins before and after the first U-turn, while there are two fins before and after the second U-turn. These differences in geometry leads to the difference in the velocity distribution. In addition, in the new design, recirculation areas (explained in Section 3.1 and shown in Figure 7 are causing higher pressure drops, leading to higher required pumping power. 


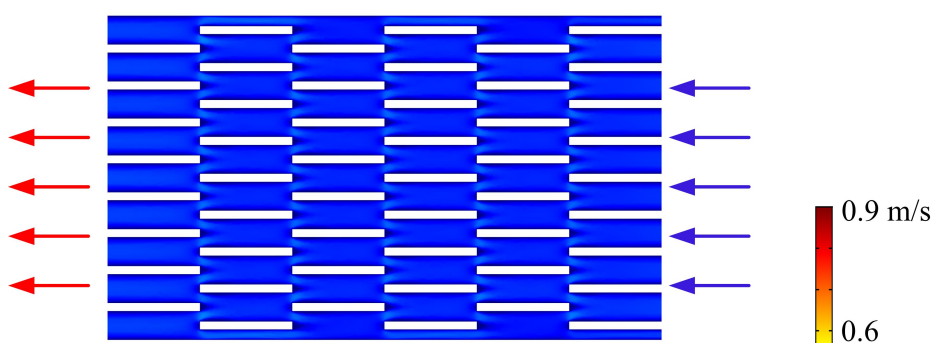

(a)

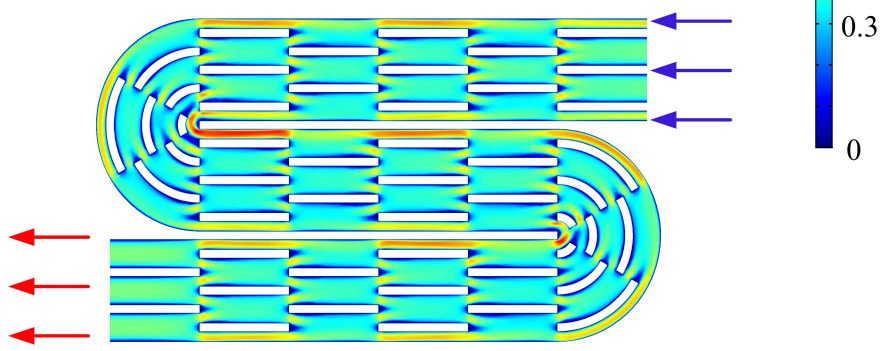

(b)

Figure 15. Velocity distribution at volumetric flow rate of $18 \mathrm{~cm}^{3} \mathrm{~s}^{-1}$ in (a) Offset strip fin design (b) New offset design.

\section{Conclusions}

In this paper, a 3-D numerical simulation is conducted for laminar forced convection of water to study a new introduced turbulator configuration for a heatsink. This new heatsink design is based on the concept of U-turn path and curvy pins in offset strip fin microchannel heatsink. IGBTs and diodes, solder, DBC substrate, baseplate and thermal grease were considered in the model simulation. Based on the results presented above, some essential conclusions are drawn as follows:

- Heat transfer coefficient through this new design increased by $65-72 \%$ compared to offset strip fin.

- The line of the local heat transfer coefficients has non-linear distribution and are much higher at the second U-turn region. U-turns play a vital role on heat transfer performance.

- A decrease in the maximum temperature of heat source (in the range of $8-11 \%$ ) can be seen in the new design compared to offset strip fin.

- Thermal resistance in the new design is lower than that in the offset strip fin (about 10-15\%).

- Pressure drop is higher in the new design than the conventional one; and this is the drawback of this new design.

- The improved heat transfer performance results from the compound augmentation of the longer coolant passage, recirculation areas and vortices along the curvy fins, centrifugal forces in U-turns and the redeveloping boundary layer.

In overall, heat transfer performance of the conventional offset strip fin design in areas of heat transfer coefficient, maximum chip temperature and thermal resistance is improved in this work.

Author Contributions: Conceptualization, A.Y. and A.S.B.; Data curation, A.Y.; Formal analysis, A.Y.; Investigation, A.Y.; Methodology, A.Y. and A.S.B.; Software, A.Y.; Supervision, A.S.B.; Validation, A.Y.; Visualization, A.Y.; Writing—original draft, A.Y.; Writing—review \& editing, A.S.B. and F.B. All authors have read and agreed to the published version of the manuscript.

Funding: This research received no external funding.

Conflicts of Interest: The authors declare no conflicts of interest.

\section{References}

1. Shu, S.; Yang, H.; Tong, C.; Qiu, F. Fabrication of TiCx-TiB2/Al composites for application as a heat sink. Materials 2016, 9, 642. [CrossRef] 
2. Pang, L.; Wang, M.; Wang, W.; Liu, M.; Wang, J. Optimal thermal design of a stacked mini-channel heat sink cooled by a low flow rate coolant. Entropy 2013, 15, 4716-4731. [CrossRef]

3. Oguntala, G.; Sobamowo, G.; Ahmed, Y.; Abd-Alhameed, R. Thermal Prediction of Convective-Radiative Porous Fin Heatsink of Functionally Graded Material Using Adomian Decomposition Method. Computation 2019, 7, 19. [CrossRef]

4. Ma, L.; Zhao, X.; Sun, H.; Wu, Q.; Liu, W. Experimental study of single phase flow in a closed-loop cooling system with integrated mini-channel heat sink. Entropy 2016, 18, 128. [CrossRef]

5. Bahman, A.S.; Blaabjerg, F. Optimization tool for direct water cooling system of high power IGBT modules. 18th European Conference on Power Electronics and Applications (EPE'16 ECCE Europe) 2016, 1-10.

6. Wang, Y.; Peles, Y. Subcooled flow boiling in a microchannel with a pin fin and a liquid jet in crossflow. Int. J. Heat Mass Transf 2015, 86, 165-173. [CrossRef]

7. Wu, T.; Wang, Z.; Ozpineci, B.; Chinthavali, M.; Campbell, S. Automated Heatsink Optimization for Air-Cooled Power Semiconductor Modules. IEEE Trans. Power Electr. 2019, 34, 5027-5031. [CrossRef]

8. Nujukambari, A.Y.; Bahman, A.S.; Hærvig, J.; Sørensen, H. A Review: New Designs of Heat Sinks for Flow Boiling Cooling. In Proceedings of the 25th InternationalWorkshop on Thermal Investigations of ICs and Systems (THERMINIC), Lecco, Italy, 25-27 September 2019; pp. 1-6.

9. Mahmoudinezhad, S.; Rezaniakolaei, A.; Rosendahl, L.A. Experimental study on effect of operating conditions on thermoelectric power generation. Energy Procedia 2017, 142, 558-563. [CrossRef]

10. Chang, Y.; Luo, H.; Iannuzzo, F.; Bahman, A.S.; Li, W.; He, X.; Blaabjerg, F. Compact Sandwiched Press-Pack SiC Power Module with Low Stray Inductance and Balanced Thermal Stress. IEEE Trans. Power Electr. 2019, 35, 2237-2241. [CrossRef]

11. Pourfattah, F.; Arani, A.A.A.; Babaie, M.R.; Nguyen, H.M.; Asadi, A. On the thermal characteristics of a manifold microchannel heat sink subjected to nanofluid using two-phase flow simulation. Int. J. Heat Mass Transf. 2019, 143, 118518. [CrossRef]

12. Bartoszewicz, J.; Bogusławski, L. Numerical analysis of the steam flow field in shell and tube heat exchanger. Arch. Thermodyn. 2016, 37, 107-120. [CrossRef]

13. Jeng, T.M.; Tzeng, S.C. Numerical simulation of laminar forced convection of pin-fin heat-sink array in a Channel by Using Porous Approach. Appl. Sci. 2015, 5, 1846-1868. [CrossRef]

14. Mohammed, H.A.; Gunnasegaran, P.; Shuaib, N.H. Influence of channel shape on the thermal and hydraulic performance of microchannel heat sink. Int. Commun. Heat Mass Transf. 2011, 38, 474-480. [CrossRef]

15. Ndao, S.; Peles, Y.; Jensen, M.K. Multi-objective thermal design optimization and comparative analysis of electronics cooling technologies. Int. J. Heat Mass Transf. 2009, 52, 4317-4326. [CrossRef]

16. Kim, H. Enhancement of critical heat flux in nucleate boiling of nanofluids: A state-of-art review. Nanoscale Res. Lett. 2011, 6, 1-18. [CrossRef]

17. Muzychka, Y.S.; Yovanovich, M.M. Modeling the $\mathrm{f}$ and $\mathrm{j}$ characteristics for transverse flow through an offset strip fin at low Reynolds number. J. Enhanc. Heat Transf. 2001, 8, 243-259. [CrossRef]

18. Ranganayakulu, C.; Kabelac, S. Boiling of R134a in a plate-fin heat exchanger having offset fins. J. Heat Transf. 2015, 137, 121002. [CrossRef]

19. Yang, F.; Dai, X.; Peles, Y.; Cheng, P.; Khan, J.; Li, C. Flow boiling phenomena in a single annular flow regime in microchannels (I): Characterization of flow boiling heat transfer. Int. J. Heat Mass Transf. 2014, 68, 703-715. [CrossRef]

20. Wieting, A.R. Empirical correlations for heat transfer and flow friction characteristics of rectangular offset-fin plate-fin heat exchangers. J. Heat Transf. 1975, 97, 488-490. [CrossRef]

21. Mochizuki, S.; Yagi, Y.; Yang, W.J. Transport phenomena in stacks of interrupted parallel-plate surfaces. Exp. Heat Transf. Int. J. 1987, 1, 127-140. [CrossRef]

22. Joshi, H.M.; Webb, R.L. Heat transfer and friction in the offset stripfin heat exchanger. Int. J. Heat Mass Transf. 1987, 30, 69-84. [CrossRef]

23. Manglik, R.M.; Bergles, A.E. Heat transfer and pressure drop correlations for the rectangular offset strip fin compact heat exchanger. Exp. Therm. Fluid Sci. 1995, 10, 171-180. [CrossRef]

24. Meana-Fernández, A.; Fernández Oro, J.M.; Argüelles Díaz, K.M.; Galdo-Vega, M.; Velarde-Suárez, S. Application of Richardson extrapolation method to the CFD simulation of vertical-axis wind turbines and analysis of the flow field. Eng. Appl. Comput. Fluid Mech. 2019, 13, 359-376. [CrossRef] 
25. Hærvig, J.; Sørensen, K.; Condra, T.J. On the fully-developed heat transfer enhancing flow field in sinusoidally, spirally corrugated tubes using computational fluid dynamics. Int. J. Heat Mass Transf. 2017, 106, 1051-1062. [CrossRef]

26. Bjerg, A.; Christoffersen, K.; Sørensen, H.; Hærvig, J. Flow structures and heat transfer in repeating arrangements of staggered rectangular winglet pairs by Large Eddy Simulations: Effect of winglet height and longitudinal pitch distance. Int. J. Heat Mass Transf. 2019, 131, 654-663. [CrossRef]

27. Roache, P.J. A method for uniform reporting of grid refinement studies. ASME-PUBLICATIONS-FED 1993, 158, 109. [CrossRef]

28. Chvála, A.; Donoval, D.; Šatka, A.; Molnár, M.; Marek, J.; Príbytný, P. Advanced methodology for fast 3-D TCAD device/circuit electrothermal simulation and analysis of power HEMTs. IEEE Trans. Electron Devices 2015, 62, 828-834. [CrossRef]

(C) 2020 by the authors. Licensee MDPI, Basel, Switzerland. This article is an open access article distributed under the terms and conditions of the Creative Commons Attribution (CC BY) license (http://creativecommons.org/licenses/by/4.0/). 